\title{
Estimating spatial variation of moisture risks in English and Welsh dwellings
}

\author{
Jonathon Taylor ${ }^{\mathrm{a}, \mathrm{b} *}$, Phil Symonds ${ }^{\mathrm{b}}$ \\ aDepartment of Civil Engineering, Tampere University, Tampere, Finland \\ bUCL Istitute for Environmental Design and Engineering, UCL, London, UK
}

\begin{abstract}
Mould growth and damp in homes can have serious adverse effects on the health of occupants. Such risks may be greatest in certain dwellings, particularly those with poor energy efficiency and ventilation, and certain locations may have greater proportions of at-risk dwellings, meaning greater risks for the resident population and a potential spatial variation in mould exposure across the country. This abstract describes the application of a building physics metamodel to around 11 million dwellings across England and Wales to estimate indoor moisture levels and mould growth risk at individual address-level. This metamodel is derived from dynamic thermal simulations of indoor temperatures, relative humidity, and surface moisture levels, predicting the mould severity index (MSI) according to building characteristics given indoor sources of moisture. We estimate a mould prevalence of $10.4 \%$ across the stock, with the greatest risks in urban areas such as London. Retrofitting does not adequately mitigate this risk without ventilation improvements, while fuel subsidies can reduce risks but with obvious energy costs.
\end{abstract}

Keywords: Building physics; mould; damp; building stock modelling

\section{Introduction/Background}

Mould growth and damp in buildings has been associated with a number of negative health outcomes, including physical health conditions such as asthma and allergies [1], as well as mental health [2]. In the UK, around 18 million people will be treated for asthma at some point in their lives - one of the highest burdens in the world - with an annual cost to the health service of around $£ 1.1$ billion a year [3]. The English housing stock is one of the most energy inefficient housing stocks in Western Europe due to its age and the Government's relatively undemanding building regulation standards [4]. This leads to a high risk of mould in English homes: around 10\% of English dwellings are thought to have mould present, with older dwellings, flats, solid-walled dwellings, and overcrowded dwellings most at risk [5].

Understanding how the risk of mould growth may vary in dwellings across the country can enable targeted actions to be undertaken, including local energy efficiency and ventilation improvements, and public awareness campaigns. This paper describes the application of a building physics metamodel to over 11 million dwellings in the Energy Performance Certificate (EPC) database [6] for England and Wales, predicting the risk of dwellings having a mould severity index (MSI) greater than one. The MSI is a simple ranking of condensation mould growth, where values greater than one represent some mould growth. Results are mapped in order to identify areas with the greatest number of at-risk dwellings.

\section{Methods}

A building physics metamodel has been developed previously for predicting overheating risk, indoor air pollution, and moisture risk [7]. This metamodel - or a model of a model - is derived from large numbers of dynamic indoor temperature and humidity models simulated using the tool EnergyPlus [8], with inputs randomly selected to represent the variation in housing characteristics across the English housing stock including fabric types and energy efficiency, geometry, floor area, and ventilation rates. The advantage of the metamodel is that is allows building performance to be rapidly estimated for a large number of dwellings, producing stock-level estimates rapidly and for a range of different scenarios. The model estimates moisture risk due to energy efficiency and background ventilation problems but does not account for risks due to wind-driven rain, failures in the building envelope or purpose-provided ventilation systems.

Here, we apply the moisture variant of the metamodel to all dwellings in the EPC database in England and Wales (Scotland has a separate database which was not available). The parameterization of the EPC database to input into the metamodel, and comparison of the EPC against other housing stock models, has been described previously by Taylor et al [7]. We examine the current housing stock, as well as changes following energy efficient retrofit of the stock (including insulation and air tightening) or increasing thermostatic temperatures by $2{ }^{\circ} \mathrm{C}$. Indoor moisture sources include those from daily cooking and showering while using extract ventilation.

\footnotetext{
* Corresponding author. jonathon.taylor@tuni.fi
} 


\section{Results and Discussion}

The results of the metamodel for the current and retrofitted stock can be seen in Figure 1, showing the percentage risk of dwellings having an MSI greater than 1, averaged by constituency (average population around 100,000). It shows a greater mould risk in certain regions of the country, such as London and Birmingham. A total of $10.4 \%$ of the stock is estimated to be at risk of mould due to the poor energy efficiency of building fabric and insufficient background ventilation, similar to the estimate from the Warm Front surveys [5]. Modelling of different adaptations show how risk can be modified, either by targeted energy efficiency retrofits of dwellings at risk of (reducing average mould growth risk by $0.5 \%$ but in some cases increasing risk), or by fuel subsidies enabling thermostat setpoint temperatures in at-risk dwellings to be increased by $2{ }^{\circ} \mathrm{C}$ (reducing risk by $1.2 \%$ but with an obvious energy cost). These results indicate how energy efficient retrofit may not necessarily lead to a decrease in mould growth, and that additional ventilation is critical for buildings undergoing retrofit in order to reduce exposure risk.
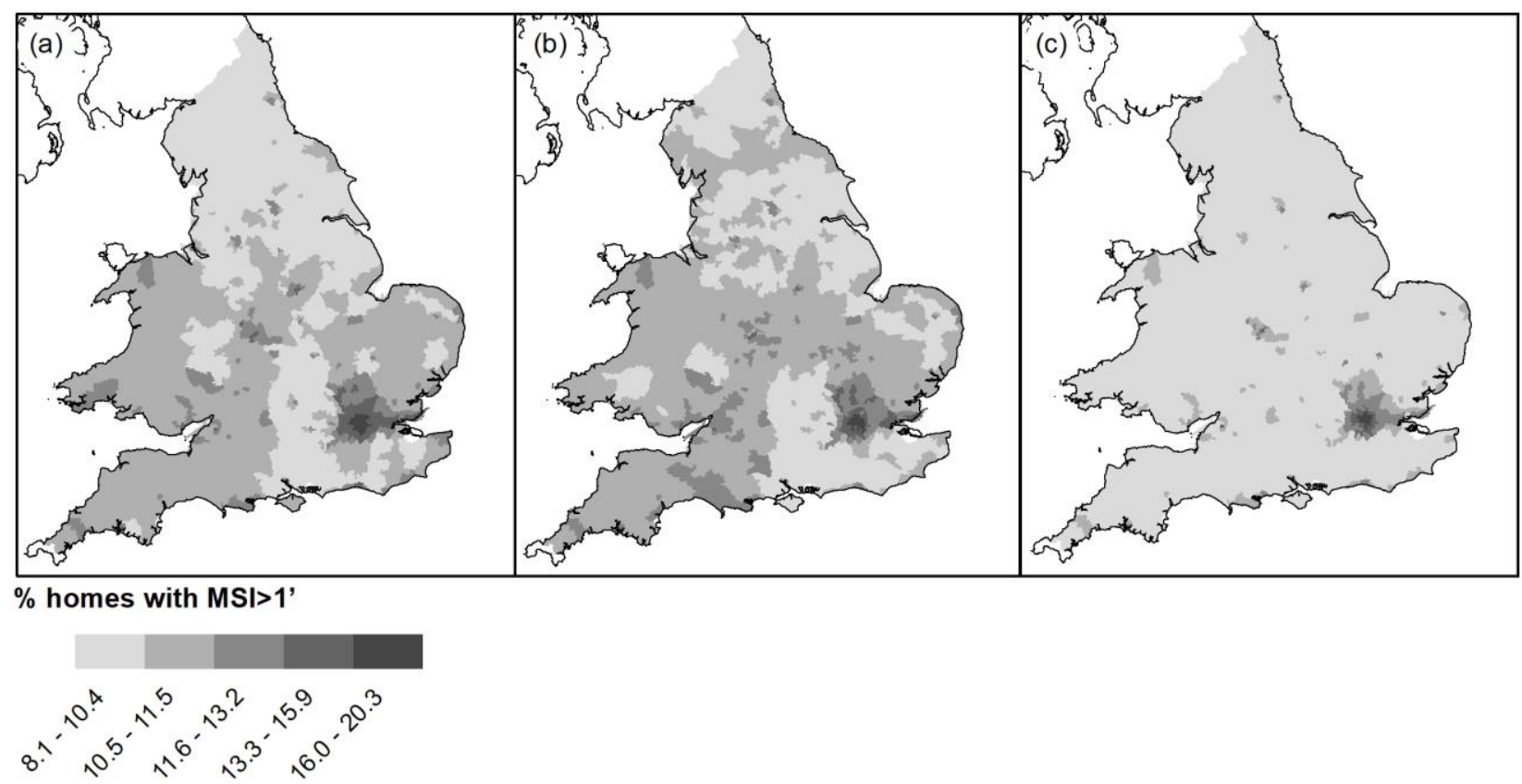

Figure 1. The percentage of dwellings with an msi greater than 1; (a) under current conditions; (b) following retrofit., and; (c) with fuel subsidies.

The described tool is useful for identifying homes and areas at risk of indoor mould growth but is limited in that it does not account for failures in building fabric and extract ventilation, nor occupant fuel poverty. It assumes retrofits do not include compensatory ventilation, which leads to only small reductions in mould growth risk and in some cases an increase following energy efficiency improvements. Future work can integrate local measures of fuel poverty, and results used to make health impact assessments of retrofit scenarios in England and Wales. Additionally, the model may be expanded to include driving rain, and overlaid with local climate data under current and future scenarios to examine how mould risk may change in the future under various climate and housing policy scenarios. The EPC data used as input into the model is known to include survey errors in building parameters [9]. Further work is required to understand the impact of these input errors on the predicted results.

\section{References}

[1] WHO. (2019) WHO Guidelines for Indoor Air Quality: Dampness and Mould,” World Health Organiszation. Copenhagen.

[2] Liddell, C. and Guiney, C., (2015) Living in a cold and damp home: Frameworks for understanding impacts on mental well-being, Public Health. 129(3) 191-199. doi: 10.1016/j.puhe.2014.11.007.

[3] Asthma UK, “Asthma facts and statistics," 2020. https://www asthma.org.uk/about/media/facts-and-statistics/. Accessed 13/10/2020.

[4] Guertler, P., Carrington, J., and Jansz, A. (2013) The cold man of Europe. Association for the Conservation of Energy (ACE), London, UK. Accessed: Mar. 31, 2020. Available: http://www.ukace.org/wp-content/uploads/2013/03/ACE-and-EBR-fact-file-2013-03-Cold-man-of-Europe.pdf.

[5] Oreszczyn, T., Ridley, I., Hong, S., and Wilkinson, P. (2006) Mould and Winter Indoor Relative Humidity in Low Income Households in England. Indoor Built Environ., 15(2) 125-135.

[6] Department for Communities and Local Government, "Energy Performance Certificates.” London, 2017, [Online]. Available: https://epc.opendatacommunities.org/login.

[7] Taylor, J., Shrubsole, C., Symonds, P., Mackenzie, I., and Davies, M. (2019) Application of an indoor air pollution metamodel to a spatiallydistributed housing stock," Sci. Total Environ., 667, 390-399. doi: 10.1016/J.SCITOTENV.2019.02.341.

[8] United States Department of Energy, (2013) EnergyPlus V8. Washington, D.C., USA. Available: http://www.eere.energy.gov/buildings/energyplus.

[9] Hardy, A., Glew, D. (2019) An analysis of errors in the Energy Performance certificate database. Energy Policy, 129, 1168-1178 